\title{
A produção subjetiva do cuidado: uma cartografia de bullying escolar
}

| 1 Pamela Lamarca Pigozi |

Resumo: Este artigo pretende compreender como a produção subjetiva do cuidado a um adolescente vítima de bullying ocorre em sua comunidade. A produçáo de subjetividades está atrelada ao cotidiano do adolescente, das relaçóes que ele constrói e do suporte gerado pela comunidade no qual está inserido. A pesquisa cartográfica buscou acessar, por meio de entrevistas semiestruturadas, as experiências, as vivências e o trajeto tecido por ele em busca de amparo. Foi discorrido sobre a violência sofrida, seus percursos, seu autocuidado e suas redes de suporte. $\mathrm{O}$ cuidado produzido mostrou-se oscilante em todo o território. A escola utilizou estratégias pontuais em relação ao bullying e o setor saúde parece não ter alcançado a dimensão psíquica do sofrimento. Entretanto, no núcleo da família e de amigos foi possível inaugurar outras formas de afeto e atenção à saúde mental do adolescente. A entrevista cartográfica permitiu esboçar, a partir da perspectiva do adolescente, o frágil cuidado oferecido pela sua comunidade em relação ao bullying. Sinaliza-se então que açôes de saúde, para serem efetivas, devem também considerar as subjetividades e as singularidades dos adolescentes, isto é, garantir um cuidado com respeito às diferenças e estímulo ao protagonismo dos jovens em seus territórios de passagem.

> Palavras-chave: bullying; adolescente; cartografia; subjetividade; Atenção Primária à Saúde.
'Escola de Enfermagem,

Universidade de São Paulo. São

Paulo-SP, Brasil (pamelapigozi@ usp.br).

ORCID: 0000-0003-0193-924X.
Recebido em: 27/02/2018

Revisado em: 25/04/2018 Aprovado em: 22/06/2018 


\section{Introdução}

Entende-se bullying como atos agressivos, repetitivos e com assimetria de poder entre os envolvidos. Nesse sentido, para configurá-lo, é necessário que as relaçóes sejam desiguais e que haja sentimento de impotência de um dos envolvidos no conflito. Também vale ressaltar que casos isolados de agressão não são considerados bullying, pois há de ter repetição nos acontecimentos (SMITH; SHARP, 1994; SMITH; MORITA, 1999).

Os jovens podem estar envolvidos de quatro formas: agressor (autor ou praticante), vítimas (ou alvo), vítima/agressor e testemunha. Neste estudo, o adolescente participante está envolvido como vítima, porém começa a adotar atitudes agressivas com outros colegas quando importunado. As vítimas, normalmente, demonstram fragilidade emocional e física, são mais introvertidas, isolam-se conforme os atos de agressão aumentam sistematicamente, não demonstram habilidades para conseguir escapar dos conflitos, não participam das brincadeiras coletivas, sentem-se inseguras, envergonhadas e tristes (SMITH; SHARP, 1994; OLWEUS; SWEDEN, 1999; SMITH; DEL BARRIO; TOKUNAGA, 2013).

Os adolescentes vítimas de bullying usualmente se sentem impossibilitados de pedir ajuda, seja por acharem que se trata de uma brincadeira (mesmo que estejam em intenso sofrimento), por carência de informação a respeito, por sentirem-se envergonhados de não poder resolver a situação sozinhos, por presumirem que sua rede de suporte não conseguirá ajudá-los, por medo de retaliação dos agressores (LOPES NETO, 2011; NASCIMENTO; MENEZES, 2013; BEAUDOIN; TAYLOR, 2006), dentre outras possibilidades que os enclausuram num experienciar tomado pela dor, podendo durar semanas ou até anos (SMITH, 2014).

A construção do cuidado direcionada ao adolescente vítima de tal agressão consiste em uma tarefa complexa, já que estamos lidando com um problema que afeta diretamente a saúde física e mental dos escolares (YEN et al., 2014). O bullying é um assunto multifacetado que envolve ações intersetoriais e não somente do ambiente escolar. A rede social do adolescente e o suporte familiar são fundamentais para que os envolvidos possam se recuperar em qualquer que seja o papel desempenhado (SMITH, 2014; LISBOA; WENDT; PUREZA, 2014).

Desse modo, o presente estudo pretende compreender como o cuidado ofertado ao adolescente vítima de bullying ocorre de forma intersetorial na comunidade. 
Tal estudo busca captar, por meio da perspectiva do adolescente, quais foram os caminhos percorridos por ele em busca de amparo, sendo que escola, setor saúde (Estratégia Saúde da Família - ESF), as amizades e seu núcleo familiar colaboram na construção desse trajeto no território. Nesse sentido, pretendeu-se cartografar a produção do cuidado subjetivo na intersetorialidade em situaçôes de bullying e tevese como aposta que as relaçóes construídas nesses cenários poderiam configurar-se como espaços generosos para produção de subjetividades.

\section{Metodologia}

A cartografia foi utilizada como referencial metodológico. Tal método se faz como pesquisa-intervenção, de modo que se propóe a mapear todo o processo do movimento de criação e continuidade dos diálogos, afetos e acontecimentos (PAULON, 2005) resultantes da interação do adolescente e dos envolvidos no seu território/comunidade.

Esse método indica que estamos todos envolvidos em um plano de forças coletivas ou vetores, o plano de consistência (DELEUZE; GUATTARI, 2011). Este é constituído por linhas mais duras (BAREMBLITT, 2012), que, no caso do presente estudo, podem ser as normas escolares, a burocratizaçáo dos cuidados conferidos ao adolescente e a relaçáo pai e filho condicionada pela autoridade, de modo que a tendência é codificar, classificar, engessar, condicionar, rotular. Já as linhas mais flexíveis e as linhas de fuga podem ser traduzidas pelas relaçóes que o próprio adolescente produz na escola, como se esquiva do bullying e como gera autocuidado. Essas linhas podem não se assujeitar ou ser dominadas, pelo contrário, podem ser criativas, inventivas e inéditas.

Todas essas forças constituem planos de experiência e do viver, sendo, assim, terras férteis para a produção de subjetividade (DELEUZE; PARNET, 1998), a qual é construída coletivamente e convocada por linhas heterogêneas a ela (ROLNIK, 2002). Essa convocação somente ocorre quando há um estranhamento ao que já constituía essa subjetividade, e isso se nomeia agenciamento, em que sempre haverá uma conexão com o fora. Tais dinâmicas e jogos de forças de diferenciação e repetição formam uma rede, um rizoma no qual tudo é conectável, não há começo nem fim, nem certo ou errado. Tudo é possível e isso constitui a subjetividade humana (DELEUZE; GUATTARI, 2011). 
Nessa direção, a entrevista semiestruturada foi utilizada para compreender os traçados do adolescente na escola, serviço de saúde e família. A escolha deste instrumento deve-se a sua potência de produzir subjetividades, revelar afliçóes e angústias acerca da problemática, traçar movimentos do usuário na rede da comunidade e deslizar nas informaçóes trazidas por ele (TEDESCO; SADE; CALIMAN, 2014; KVALE; BRINKMANN, 2009). A produção de subjetividades está atrelada ao cotidiano do adolescente, das relações que ele constrói, do cuidado e atenção gerados pela comunidade na qual está inserido, da confiança que surge conforme este caminha em seu território (MARTINES; MACHADO, 2010).

$\mathrm{Na}$ pesquisa cartográfica, a entrevista não pretende somente acessar a experiência por meio do conteúdo da linguagem, vai além, já que também visa alcançar a expressão. O conteúdo é da ordem das palavras, dos sentidos e da expressão, que é relativa aos signos sensíveis, como a respiração pausada, o ritmo e a velocidade da fala, das pausas, das faces de surpresa, de angústia, do "não quero mais falar", da tristeza e da alegria (TEDESCO; SADE; CALIMAN, 2014).

O exercício de cartografar exige um deixar afetar-se. De modo que, nesse plano coletivo de forças, o pesquisador náo se isola do processo ou posiciona-se como mero expectador. Ao contrário, o cartógrafo adota uma postura disponível e aberta ao inédito, dando passagem para produção de si e do mundo (BARROS; SILVA, 2014).

Tendo isto em vista, os encontros com o adolescente foram realizados em um local de sua escolha, que foi sua casa, e em seu ritmo, de modo que não foi definido a priori o número exato de entrevistas para a produção dos dados; conforme contemplaram o objetivo proposto, não houve a necessidade de repetir a aplicação do instrumento. Somado a isto, toda a atividade foi acordada com o adolescente, respeitando a ética e o sigilo do entrevistado (aprovação por parte do Comitê de Ética, conforme a Resolução no 466/2013, número do parecer 435.411).

$\mathrm{O}$ assunto bullying poderia conferir densidade e dureza ao diálogo, preferiu-se, portanto, iniciar a entrevista com uma conversa informal, discorrendo acerca do cotidiano do adolescente, suas relaçóes na escola e família, suas experiências diárias e até do que mais gostava de fazer com seus amigos. Logo, pretendeu-se deixar fluir suas vivências na comunidade, tanto na escola quanto nos caminhos que percorreu à procura de amparo, podendo ter recorrido ao profissional da saúde, ao professor ou ao amigo da escola. As perguntas disparadoras foram feitas sutilmente entre uma fala e outra, como: 
1. Conte-me mais sobre estas situaçôes de bullying (o termo bullying às vezes, era substituído por "tirar sarro", pois percebeu-se que assim o adolescente mostrava melhor compreensão).

2. Há quanto tempo você vivencia estas situaçôes?

3. Como você lida com isso? Você já contou para alguém?

4. Seus professores ou pais sabem que você sofre bullying?

A intenção era compreender quais são os pontos de suporte que atenuam esse sofrimento. Se não existem, como faz o adolescente para suportar tamanha angústia? De que mecanismos ele lança mão para conviver com seus pares? Seu aprendizado na escola é afetado? E se é afetado, o que tem feito a escola? O que tem feito sua família? Qual é a sua rede de apoio?

Com permissão do adolescente e de sua mãe, durante as entrevistas, foi utilizado um gravador, para facilitar a transcrição das falas, as quais foram descritas verbatim. Imediatamente, após o término, outros elementos extralinguísticos (expressão, entonação de voz, ritmo da fala) foram anotados em diário de campo. Ao todo, foram três encontros, com duração média de 15 minutos. Teo e Emília são os nomes fictícios do adolescente e sua mãe, respectivamente. A aproximação da pesquisadora ocorreu por meio da ESF, que se localizava na área de abrangência onde residia o adolescente.

Serão apresentadas e discutidas as três entrevistas realizadas com Teo, os vários aspectos referentes à produção subjetiva do cuidado, de modo que será discorrido sobre sua história e suas experiências nos diversos locais em que transita, com foco nas cenas de bullying escolar. Além disso, será discutido seu autocuidado referente à vitimização e suas redes de suporte e proteção, que envolvem os amigos, a escola, o setor saúde e sua família.

Este estudo é parte de uma Tese de Doutorado realizada em um pequeno município do Estado de São Paulo, no período de fevereiro de 2012 a junho de 2016.

\section{O entrevistar cartográfico: um pouco sobre a família e o bullying escolar}

Teo, aos 7 anos de idade, decidiu morar com seu pai, seus dois irmãos (um mais novo e outro mais velho) e a esposa do pai. Relatou passagens conflituosas em seu relacionamento com o pai, as quais captaram atenção, talvez pelo fato de haver conflito e dor naquele emaranhado de palavras. Já na adolescência, aos 11 anos, retornou, 
repentinamente, à casa da mãe. Teo possuía alopecia total (ausência de pelos em todo corpo) e, nessas falas, é marcante o modo como ele entende a causa desse problema:

Teo: Meu pai cortou meu cabelo, daí tinha uma parte torta, daí eu fui acertar, acabei cortando um pouquinho, daí ele me bateu e me jogou dentro do rio. Às vezes, dá impressão que ele não gosta de mim [...]. Porque tem vezes que eu não faço nada e ele vem e me bate.

Teo também complementou que uma semana após esse acontecimento com o pai, seu cabelo caiu. E a lembrança da data era precisa, referindo ter sido em maio de 2013, no Dia das Máes.

Além da violência familiar, suas falas começaram a configurar um tipo de violência comum no meio escolar, o bullying, que possui como uma das características o fato de ser repetitivo e com assimetria de poder entre os envolvidos (OLWUES, 1999; SMITH, 2014).

Teo: Eles zuaram bastante comigo. Uns três meses. Um dia, eu falei pra minha mãe que não queria ir mais para escola, porque eles ficavam zuando e me atrapalhando.

Pesquisadora: Entendi. E você acha que isso influenciou nas suas notas?

Teo: Caíram, fiquei sem nota este ano.

Os trajetos tecidos pelo adolescente desenham uma cartografia sinuosa, que ora "não vinha” para a entrevista, pois "estava brincando", ora proferia relatos de um seio familiar que pouco o protegia e gerava sofrimento. Teo estava com a ponta dos pés na "corda bamba". O cenário habitado por ele perfazia traçados com vulnerabilidade e exposiçáo a todo o momento.

Não há precisão nas falas, nem exatidão; o adolescente pende a resposta para o "sim", de repente pende para o "não", o "não sei" é frequente. A linguagem é viva da ordem da experiência e da processualidade, o que faz da pesquisa um ato puramente cartográfico, que acompanha a vida em carne viva, acontecendo.

A direção impressa na pesquisa cartográfica, entretanto, é outra: a precisão não é exatidão, no sentido de representar de forma fidedigna a realidade pesquisada por meio de passos a serem seguidos. Ela estaria próxima dos movimentos da vida. Da normatividade do vivo, e é tomada como compromisso e interesse, intervenção (BARROS E SILVA, 2014, p. 131).

Seus relatos estavam encarnados de violência travestidos por um cenário de descuidos. Expressava-se, fazia paradas, respirava curto e parecia ter medo de contar o que vivia. Tinha uma feição de "posso falar mesmo?", medo de estar "errado" e inadequado. Mostrava receio de sofrer ainda mais violência simplesmente por contar sua história. 
A princípio, para além de um descuidar, há algo que extrapola, que é a violência no seio familiar. Teo é agredido pelo pai e, após um desentendimento, este o joga num rio frio e escuro, à noite. A partir desse conflito, o adolescente, envolto nesse contexto, inicia a produção de mapas diversos. De forma interessante, tal cena de violência (com o pai) desencadeou uma série de outras cenas conflituosas, configurando esses mapas.

Deleuze concebe mapa como algo conectável, aberto, em movimento, que pode ser rompido, rasgado, reconfigurado, criado por grupos, por pessoas, construído como ação político-social (DELEUZE, 2011). E assim era Teo, desenhando seus mapas de medo, de tristeza, de exposição, de perda, de bullying, de resistência, de adaptação, de estranhamento, da falta de vontade, da escola que não acolhe, do não querer ir para a escola, dos amigos no campinho, do bater cartas, do corpo nu.

Vale ressaltar que o manejo cartográfico da entrevista possibilitou os dizeres de Teo, que, ao revisitar sua história, pôde expressá-la de seu modo, experienciando-a num contexto de escuta atenta e acolhimento. Evitou-se estímulo a um discurso unificador ou totalizante, bem como condução diretiva em busca de pura informação (PASSOS; KASTRUP; TEDESCO, 2014). A intenção era do livre tracejar do adolescente que revisatava sua história e já criava outras possibilidades de expressão enquanto conversava, de modo que não era vítima ou mero expectador, mas protagonista de seus relatos.

Foi sugerido algo da escolha dele, depois que a primeira entrevista foi tomada de um tanto de seriedade para um menino de 11 anos. Portanto, a partir da segunda entrevista, foi acordado iniciar as conversas "batendo" figurinha.

Em uma cartografia, o participante pode expressar-se por sua vontade de viver, de resistir, de esquivar-se, esticar até quando pode, criar até onde suas possibilidades o permitirem. Até onde a vida pode passar ou resistir? Isso se torna o germe do método cartográfico, o cerne, que se cria e se dá nos fluxos de intensidade das falas e dos corpos (OLIVEIRA; PARAISO, 2012).

\section{Teo e suas redes de suporte: o cuidado cambaleante}

\section{$\mathrm{O}$ autocuidado}

Nesta cartografia dançante, de puxa-estica e esquiva, o corpo de Teo demonstrava o quão insatisfeito estava com o mundo, mas, apesar disso, também era instrumento de luta. Teo fazia-se rizoma, conectado o um território plural de infinitas possibilidades. 
Deleuze considera que o mapa faz parte do rizoma. "Um rizoma pode ser rompido, quebrado em um lugar qualquer, e também retoma segundo uma ou outra de suas linhas e segundo outras linhas. É impossível exterminar as formigas, por que elas fazem um rizoma animal do qual a maior parte pode ser destruída sem que ele deixe de se reconstruir" (DELEUZE; GUATTARI, 2011, p. 22).

$\mathrm{O}$ adolescente não enrijecia, ele continuava no seu mapear, e tentava da melhor forma. Emprestando uma frase de Deleuze e Guattari (2011, p. 48): "Nunca suscite um general em você. [...] Um rizoma não começa nem conclui, ele se encontra sempre no meio, entre as coisas, inter-ser, intermezzo." Teo era rizoma. Ele parecia não tentar entender e, apesar dos conflitos, ele não os totalizava, na verdade, estava sempre no entre.

Vê-se a seguir como Teo lida com o bullying e quais são as possibilidades que ele cria sozinho. Não se trata de compreender se essas decisões ou desenhos produzidos pelo adolescente são adequados mediante as situaçóes de bullying, o que se pretende é deslizar sobre as linhas do experienciar protagonizadas por ele.

O adolescente conecta-se e convoca uma rede de proteção e suporte: as amizades, a mãe, a escola e o serviço de saúde. Essa malha protetora, ora está presente, ora frágil, ora quase inexiste. Apesar disso, a cartografia de Teo é escrita margeando os fios de tal rede, que suporta, mas também deixa cair.

\section{O Amigo}

Teo contou de suas amizades e suas brincadeiras:

Pesquisadora: Você tem mais algum amigo na escola, quantos amigos você tem na escola? Teo: Que não zoa comigo?

Pesquisadora: Sim.

Teo: Três.

Pesquisadora: E o que vocês costumam fazer?

Teo: Jogar bola. Com o Alê.

O sentir-se isolado, escutar apelidos odiosos, ter seu material por diversas vezes pego sem permissão (como zombaria) e proteger-se com o boné azul para não expor a nudez produziam um profundo sentimento do não querer estar no cenário escolar. Contudo, Alê (o amigo) e Teo fazem desvios nessa cartografia atravessada por atos torturantes. $\mathrm{O}$ amigo produz e coproduz outras linhas de vida. Teo se firma e 
reafirma no amigo, e essa relação é recíproca [posto que a história de Alê também é marcada por desproteção e negligência familiar].

Os relatos sobre o amigo Alê pareciam ser fundamentais para a resiliência de Teo quando era vitimizado, pois, além de ser uma escuta atenta, o amigo o defendia em alguns momentos e ainda o aconselhava sobre como deveria se comportar mediante tais situaçôes. Independentemente se esses conselhos eram "adequados", efetivos ou não, a presença do amigo desloca uma subjetividade assujeitada pelos processos de bullying para uma subjetividade de afetividade e confiança que se faz através da fala, do desabafo, da busca pelo "ombro amigo". Nesse sentido, há uma divisão do sofrer, uma com-divisão, um com-sentir da experiência (AGAMBEN, 2014), e nessa cartografia com-vivida produz-se um outro espaço com-partilhado no seio escolar.

Os amigos não condividem algo (um nascimento, uma lei, lugar, um gosto): eles são com-divididos pela experiência da amizade. A amizade é essa condivisão que precede toda divisão, por que aquilo que há para repartir é o próprio fato de existir, a própria vida (AGAMBEN, 2014, p. 71).

A amizade compóem esse espaço, um espaço suportável. Colabora na produção de subjetividades libertas, do adolescer, ao dar passagem para linhas de fuga, que escapam produzindo outras formas de sentir, agenciando outros modos de agir e de resistir. Bater cartas, jogar bola, conversar e chorar são linhas fluidas que costuram este mapear. Teo lançava mão de afetos que resistiam, "iam contra a maré". Cuidado (autocuidado) que luta, não se adapta, nao se deixa dominar (MACHADO; COLVERO, 2013).

Segundo Deleuze (2002), Espinosa sugere que os corpos trazem em si a capacidade de afetar-se mutuamente quando se encontram um com o outro. Se os encontros produzem "alegria", aumentam a potência do corpo de agir sobre o mundo, se produzem "tristeza", reduzem sua potência. Ora, o filósofo fala do nosso cotidiano e do quanto somos afetados pelos inúmeros encontros com pessoas, coisas, ideias, falas, que vão se compondo ou não com a forma como atuamos sobre a realidade.

E assim eram os encontros com Alê, leves, menos tristes, mais alegres. Alê, além de conferir outro tom à realidade difícil do colega, também atuava como defensor de Teo ao colocar-se entre o adolescente e os outros que o discriminavam, pedindo para cessarem os xingamentos. Em relação a isso, estudiosos relatam que o adolescente vitimizado apresenta menos problemas emocionais, melhor autoestima e é menos rejeitado pelos pares quando possui um colega que o defende (SAINIO et al., 2011). 
Outros autores reforçam que o nível de vitimização torna-se menos frequente em uma sala onde o comportamento mais comum dos alunos de um modo geral é o de ir em defesa dos colegas ao invés de aliar-se ao agressor (SALMIVALLI; VOETEN; POSKIPARTA, 2011).

\section{A família}

Além da amizade, Teo cresce em outras possibilidades de amparo, convoca Alê, mas também a mãe. Teo expande-se em sua multiplicidade, e o que precisamente impulsiona tal multiplicidade são os agenciamentos. Estes que se traduzem como "o crescimento das dimensôes em uma multiplicidade, que muda necessariamente de natureza à medida que ela aumenta suas conexóes" (DELEUZE; GUATTARI, 2011, p. 24). Como dito anteriormente, Teo era rizomático, crescia em sua forma de traçar caminhos, traçava linhas de fuga, linhas que faziam contínuas tentativas de escapar do sofrer, metamorfoseava.

Os cuidados direcionados a Teo geralmente eram protagonizados pelo descuidar do pai, mas despencavam para outros territórios convocados pela mãe. Núcleo familiar que foi clausura, mas tornou-se refúgio. Nesse sentido, a família pode coatuar na construção de subjetividades não assujeitadas, oferecer escuta, fazer escolhas, trilhar o caminho conjuntamente, acolher a dor, ser coadjuvante da mudança (COLVERO et al., 2013).

E nesta cartografia havia Emília (a mãe). Estava atenta e visível. Vê-se que a busca pela rede de saúde como possível amparo ao adolescente é liderada por ela, que o faz indo e voltando exaustivamente, pois mediatizada pelo desejo de cuidar, costurava redes com a escola e com o serviço de saúde e, além de conectar os fios dessa costura, também apertava os nós e fazia-se "suporte firme" nas idas e vindas à procura de ajuda tanto na escola quanto no setor de saúde. Emília tornava a cartografia de Teo mais leve ao atenuar seu sofrimento. Cuidava de acordo com suas possibilidades e o fazia preciosamente - confiança e afeto advindos da mãe margeavam os mapas da adolescência de Teo.

Emília faz rearranjos neste rizoma, inicia uma produção pautada no desejo de cuidar, inventa cuidado e cria rotas de fuga. De acordo com Franco et al. (2009, p. 32), "O desejo é o núcleo propulsor da produçấo social pelos sujeitos individuais e coletivos". Assim, ele produz subjetividades e opera movimentando-se nos espaços mediatizado pelo que antes e durante afeta um sujeito, de modo que se exterioriza 
através da singularidade, o que lhe faz único, mediatizado por algo que ninguém sentiu, senão o próprio sujeito. Manifesta-se por desvios inundados de vontade, que é o que constitui os processos de transformação e de mudança.

Nesse sentido, a mãe opera interrogando a escola e convocando o serviço de saúde, e, assim, faz autogestão deste cuidar ao inverter lógicas consolidadas e constituídas de um fazer cuidado nesses setores (escola-saúde). Na leitura de Baremblitt (2012), "autogestão" diz respeito a readquirir seu poder de auto-organização, de gerenciar modos de estar e de viver, fazer-se, de modo livre e original, modos de cuidar, modos de experienciar. Nesse caso, modos de caminhar não estagnado nas poucas alternativas apresentadas a ela no circuito escola-saúde, mas agenciados através de relações horizontais inventivas entre os sujeitos e as instituiçóes.

\section{A escola}

Apostou-se que a escola e o serviço de saúde (que será descrito porteriormente) poderiam coproduzir suporte e estar atentos ao sofrer emocional do adolescente. $\mathrm{Na}$ perpectiva da atenção primária, a Estratégia Saúde da Família e a escola tornamse pontos essenciais em uma rede intersetorial que deve articular-se para oferecer cuidados à saúde do adolescente (BRASIL, 2012), principalmente se este se mostra vulnerável como Teo.

Entretanto, em todo o processo da entrevista, segundo a percepção de Teo, tais setores produzem um cuidar fragilizado e, em alguns momentos, paradoxalmente, produzem sofrimento.

O adolescente discorre sobre como a diretora e a escola, de modo geral, lidam com o bullying entre os alunos:

Pesquisadora: E o que o pessoal da escola [educadores] faz nestas situaçóes [bullying]?

Teo: A diretora conversa sempre, só que eles não escutam... tem uns que zuam até com os professores.

Pesquisadores: E o que o professor faz?

Teo: Ele fala pro diretor, daí o diretor conversa, só que não adianta. Ela (diretora) fala para parar de zuar com as pessoas que têm problema, que um dia pode acontecer com eles, com os filhos deles.

Apesar do empenho da diretora e dos professores com esse subtipo de violência entre pares, as açóes da escola restringiam-se a conversar depois que a situação de violência havia ocorrido. Parece não haver nenhum programa ou atividade de 
promoção a um clima escolar favorável e também nenhum suporte restaurativo com os alunos que sofrem o bullying e com aqueles que também o cometem. Além disso, as açóes são pontuais, advindas somente da diretora, de modo que os professores parecem não estar preparados para lidar com o problema e "passam-no" para o nível superior. Nota-se a ausência de amparo ao aluno vitimizado, ao causador da violência e ao professor, para que este possa lidar adequadamente com tais situações.

Se, por um lado, o clima escolar saudável favorece o aprendizado e o bem-estar escolar, sabe-se que atual mente parte do sistema educacional é composta por professores cansados que, além de ministrar o ensino, também precisam lidar com incidentes de agressividade em sala de aula e alcançar a expectativa dos pais e da comunidade. Nesse âmbito, por uma infinidade de fatores que não cabe aqui descriminar, indica-se a falta de capacitação (acerca de assuntos específicos como as violências escolares) e atenção às condições de trabalho dos docentes, aspectos estes que produzem o sofrer do discente, mas também do docente (LISBOA; EBERT, 2012).

Linhas duras e automatismos cotidianos que compõem processos pautados em relaçôes de poder com pouca autonomia do docente o impulsionam a reproduzir um descuidar, um não ver e então se passa o problema do bullying para um nível superior. Como reflexo desse cenário, Teo, nas entrelinhas, convocava o cuidado da escola, através do baixo rendimento acadêmico, da frágil rede de amigos, dos sintomas de mal-estar, das faltas constantes e da agressão aos colegas. Curiosamente, esta corporalidade, tomada por súplica, não ecoa, e então, no limite do insuportável, a denúncia é mediatizada pela mãe.

Faz-se, aqui, uma conexão com os escritos de Maffesoli (2007, grifo do autor), que diz que "os amadores do mundo" são os mais legítimos opositores de tudo que é consolidado e instituído. Eles engendram processos de denúncia, propagam, evidenciam e difundem processos ocultos nas instituiçóes esclerosadas.

Outros autores (PERES; MARTINS, 2012) citam que as subjetividades produzidas na escola integram um sistema complexo, com elementos subjetivos do social e do individual. Destacam que as atuais políticas públicas, ao padronizar as escolas, negligenciam esses elementos, essas subjetividades, que são particulares a cada comunidade, escola e alunos que ali estão inseridos. Dizem que a escola pode refletir essas subjetividades individuais e coletivas, ser um amplo reflexo de membros que carregam preconceito e discriminação, tornar-se espaço de produção de violência numa escala maior (PERES; MARTINS, 2012). 
Nessa perspectiva, destacam o necessário reconhecimento das singularidades de cada escola e dos sujeitos que fazem parte dela. Reconhecer a violência escolar é ter que reconhecer a subjetividade dos membros que a compóem, seus afetos, sua produção social, sua historicidade familiar e individual. Assim, seria possível trabalhar com as potencialidades de cada espaço, pois se há produção de violência, há de haver também produção de alegria, criatividade, autonomia e liberdade em maior proporção.

Como possibilidade de transformação dessa realidade social, alevantam (PERES; MARTINS, 2012) que as políticas públicas podem impulsionar mudanças no espaço escolar, entretanto, os acordos e pactuaçóes dos agentes envolvidos, nos quais as subjetividades destes deveriam ser postas e consideradas, é o que de fato poderá alavancar transformações. Reafirmam (PERES; MARTINS, 2012) tal indicação, salientando a criação de estratégias de acolhimento no espaço escolar, no sentido de receber/acolher a diferença do outro, de garantir um espaço em que os sujeitos sejam reconhecidos e respeitados em suas particularidades, livres de quaisquer tipos de violência e discriminaçóes.

\section{O Setor Saúde}

Considerou-se que os atores do espaço escolar como também os que integram o serviço de saúde poderiam atentar-se às subjetividades produzidas nos sujeitos e pelos sujeitos. Entretanto, nota-se fragilidade da rede de saúde em perceber Teo nessa perspectiva. Após a queda de seus pelos, ele conta sobre o posicionamento de sua mãe perante o problema.

Pesquisadora: E o que sua mãe fez depois disso?

Teo: Marcou uma consulta pra ver o que que era. Primeiro nós fomos no hospital X, daí lá não dava, daí eu fui no hospital Y e só tem vaga pro ano que vem, depois esses dias agora eu fui no hospital Z.

Pesquisadora: E como está isso agora?

Teo: Não sei.

Pesquisadora: Em algum momento, no hospital X ou no $\mathrm{Y}$, algum profissional abordou outras questóes de saúde além da perda de pelos?

Teo: Eu não lembro. Só trataram do cabelo.

Pesquisadora: Teo, então vocês estão até agora tentando um médico. Faz quantos meses? Teo: Faz uns sete. 
Pesquisadora: Como você se sente de não estar conseguindo?

Teo: Muito mal, queria que arrumasse rápido.

Pesquisadora: Alguém já te explicou sobre a queda do cabelo?

Teo: Me falaram que por causa que eu passei estresse, daí meu cabelo caiu.

Pesquisadora: Quem falou isso pra você?

Teo: A médica do hospital Y. Fomos para o hospital Y, mas tinha vaga só para outro ano.

Conforme Teo relata seu trajeto em busca de atendimento para a alopécia, ele deixa claro seu descontentamento e sua expressão é de "espera". Linhas centradas no atendimento vertical e médico-curativista, na Estratégia Saúde da Família, atravessam o cuidar e pousam seu foco de ação no diagnóstico da alopécia. Cria-se mais um problema para Teo, o do menino que tem alopécia e a busca insana para "arrumar rápido", nas próprias palavras de Teo. Nessa direção, Lage, Moura e Horta (2012) afirmam que quando se inicia a produçáo do cuidado a partir do adoecer (agravo ou diagnóstico), corre-se o risco de rotular o jovem, reduzindo-o à esfera da doença, além de ser estratégia pouco efetiva.

Teo demonstrava a perspectiva de ter seus pelos e cabelos novamente e a espera prolongava-se por sete meses com inúmeros encaminhamentos à atenção especializada, a pelo menos $50 \mathrm{~km}$ da sua residência. A rede de apoio em saúde não conferiu nenhuma resposta a Teo, pelo contrário, produziu busca cansativa por resposta/atendimento/acolhimento. A saúde tornou-se espera e angústia. Arrisca-se a dizer que a procura por atendimento reforça o sofrimento de Teo, pois, além de não dar respostas que aliviem seu pesar, também não trata o corpo físico e sequer olha para seu sofrimento psíquico mediante a perda de pelos e do bullying.

Sabe-se que a Atenção Básica é a preferencial porta de entrada da rede de atenção à saúde e deve coordenar o cuidado em saúde (BRASIL, 2012). Nessa malha tecnológica de possibilidades em saúde, pressupõe-se que esse nível de atenção dever estar atento aos problemas de ordem física, mas também deve integrar o cuidado da dimensão psicossocial. Em suma, deve criar condiçóes que viabilizem o acolher do sofrimento de qualquer ordem.

Entretanto, o adolescente tornou-se sujeito do sofrer. Tais linhas do sofrer correm seguras na produção de subjetividades tomadas por angústia, a qual remete ao sentimento de estreitamento, apertamento, restrição e intensa aflição (CUNHA, 1997). 
O cuidar do sofrer e das subjetividades é desafiador e convoca a equipe a construí-lo conjuntamente com o usuário, a cocriar outras possibilidades de vida (MACHADO; COLVERO, 2013; COSTA et al., 2015). De modo que não se trata apenas de curar uma morbidade, circunscrevendo este cuidar ao corpo físico, deve ir além, muito além, deve flertar com a angústia e acolhê-la.

A noção de subjetividade é intrincada por processos criativos e poder de criação, deve abarcar objetos distintos, o social, o biológico, o culturtal e o psíquico. Há elementos do visível, do invisível, do dizível e de pura corporalidade. O cuidado da subjetividade convoca a atenção, o olhar vibrátil sobre o outro, aos seus signos, ao que se quer gritar, expressar e muitas vezes ao que se quer calar (MACHADO, 2009).

Este cuidar nao é dado a priori, pois exige tentativas repetitivas e olhar sensível às diferenças. Pode e deve ser pintado por diversas mãos dos variados membros de uma equipe de saúde. "O cuidado das subjetividades é um processo de criação. [...]. É um cuidado que só se realiza se for problematizado na dimensão de pôr o usuário [...] como protagonista" (MACHADO; COLVERO, 2013, p. 33).

O cuidar de Teo exigia olhar refinado, tempo de escutar, tempo de falar, tempo de calar, e se o tempo de calar persistisse, haveria de ter tempo de criar dispositivos de acolhimento adequados para o adolescente, a fim de abrir passagens para afetos, do que fica à margem, do não percebido, tocar na experiência de bullying, fazê-la emergir e, enfim, ser cuidada. Este cuidar atento dos profissionais exige trabalho e mais trabalho, insistência para fazer vazar uma possível mudez/nudez opressiva que compunha um mar de subjetividades estreitas que achatavam o mundo de Teo.

A construção do processo de confiança é fundamental nessas situações de bullying, já que o adolescente envolvido com esses conflitos está com medo e inseguro (PIGOZI; JONES BARTOLI, 2016). Pode-se começar por estar disponível e visível, para que o adolescente saiba que existe alguém em quem ele possa confiar e contar do seu sofrer.

O cuidado subjetivo, que é da ordem das subjetividades, segundo Machado e Colvero (1999), está para além das normas, dos protocolos e da rotina de atendimento, ao contrário, desliza e pode escapar rapidamente. É preciso atenção ao existencial do sujeito. Olhos e ouvidos devem estar afinados para captar algo além dos sinais e sintomas (da alopécia ali escancarada, já contada pela nudez). Além dos elementos que indicariam uma normalidade morfofuncional (AYRES, 2004). Além fundamentalmente quando se trata de um adolescente e ainda mais além quando 
se trata de bullying entre adolescentes, já que o corpo encolhido, a voz baixa e a profunda introversão não são ruídos, são elementos-chave para se perceber a agressão e poder construir o cuidar.

Mas é preciso insistir: a subjetividade não é algo abstrato, trata-se da vida, mais precisamente, das formas de vida, das maneiras de sentir, de amar, de perceber, de imaginar, de sonhar, de fazer, mas também de habitar, de vestir-se, de se embelezar, de fluir etc. (PELBART, 2000, p. 37).

A saúde do adolescente, principalmente no tocante ao sujeito vulnerável em situações de bullying, requer a criação de dispositivos de fazer cuidar, que podem acontecer através do acolhimento, empatia, escuta sensível, rodas de conversas, intersetorialidade entre escola-família-serviço de saúde, entre outros. Esse cuidado deve diluir as linhas homogêneas do saber máximo e inquestionável do profissional de saúde centrado em "resolver" o caso, um cuidado negociado com o sujeito, protagonizado por ele, que perpassa pelos seus modos de levar a vida, seus projetos de vida (HORTA; SENA, 2010; LAGE; MOURA; HORTA, 2012).

\section{Considerações finais}

Este estudo pôde cartografar, por meio de relatos de um adolescente vítima de bullying, seus trajetos em busca de amparo. Descreveu que o cuidado subjetivo tecido pelas mãos dos variados pontos de suporte de sua comunidade foi protetivo, mas também frágil e descompassado. Nesta cartografia, foi visto que o bullying gerou contínuo sofrimento, contudo, o autocuidado que Teo produziu - a partir da mãe, do amigo e do boné azul - pareceu ter sido sustentador e apaziguador, pois o conectava com a escola. Entretanto, as instituições escola e saúde parecem ter intensificado o sofrimento. Considerando que a produção de um cuidar subjetivo e afetuoso adveio do próprio sujeito e de sua rede familiar e de amigos, aposta-se em programas e políticas públicas que tenham como norte investir no protagonismo do adolescente, seu modo de estar, sentir e viver.

Alevanta-se a necessidade de programas com foco no bullyinge nas demais violências que circurdam os jovens no Brasil. Mas, sobretudo, sugere-se a contextualização desses programas às vivências dos adolescentes, as suas singularidades, as suas diferenças socioculturais, as suas subjetividades. Desse modo, alguns questionamentos podem ser postos: "Quais são seus quereres, o que os movimenta na comunidade? O que gostam de fazer, o que definitivamente não os agrada? Podem eles colaborar para 
a construção de uma escola livre de violência? Como podem colaborar? Quais as suas potencialidades? Como podem produzir afetividade? Há espaço para o afeto na escola? Como seriam esses espaços, como e quem pode produzi-los?”.

As respostas poderiam indicar a qualidade e o modo de operar das instituiçóes que os jovens a partir de si construiriam. Além disso, tais perguntas poderiam conduzir a caminhos que facilitem a elaboração de um cuidar para e com o adolescente. Cuidado que possa resistir a um olhar centrado no adoecer e que seja impedidor da marginalização do jovem a sua própria vida. Cuidado construído pelo olhar atento ao mal-estar, às notas baixas, a "um não quero estar lá". Cuidados das subjetividades, daquilo que não exatamente está escancarado, mas que está pulsante, lacerando infinitas possibilidades de liberdade e alegria.

\section{Referências}

AGAMBEN, G. O amigo \& O que é um dispositivo? Trad. de Vinicius Nicastro Honesko. Chapecó: Editora Argos, 2014.

AYRES, J. R. C. M. O cuidado, os modos de ser (do) humano e as práticas de saúde. Saúde e Sociedade. São Paulo, v. 13, n. 3, p. 16-29, 2004.

BAREMBLITT, G. F. Compêndio de análise institucional e outras correntes: teoria e prática. 6. ed. Belo Horizonte: FGB/IFG, 2012.

BARROS, M. E. B.; SILVA, F. H. O Trabalho do cartógrafo do ponto de vista da atividade. In: PASSOS, E.; KASTRUP, V.; TEDESCO, S. (Org.). Pistas do método cartográfico: a experiência da pesquisa e o plano comum. Porto Alegre: Sulina, 2014, v. 2, p. 128-152.

BEAUDOIN, M.; TAYLOR, M. (Org.). Trabalhando com cada aluno em torno da questão do bullying. In: Bullying e desrespeito: como acabar com essa cultura na escola. Trad. de Sandra Regina Netz. Porto Alegre: Artmed, 2006.

BRASIL. Ministério da Saúde. Secretaria de Atenção à Saúde. Departamento de Atenção Básica. Política Nacional de Atenção Básica. Brasília : Ministério da Saúde, 2012. 110 p. (Série E. Legislação em Saúde).

COLVERO, L. et al. Cotidiano de cuidados em saúde mental na Atenção básica à saúde. In: MACHADO, A. L.; COlVERO, L.; RODOlPHO, J. R. C. (Orgs). Saúde Mental: cuidado e subjetividade. São Caetano do Sul, SP: Difusão Editora; Rio de Janeiro: Editora Senac Rio de Janeiro, 2013.

COSTA, D. K. G. et al. Concepçóes e práticas dos profissionais de saúde acerca da violência intrafamiliar contra crianças e adolescentes. Trabalho Educação e Saúde. Rio de Janeiro, v. 13, suppl. 2, p. 79-95, 2015. 
CUNHA, A. G. Dicionário Etimologico Nova Fronteira da lingua portuguesa. Rio de Janeiro: Nova Fronteira, 1997.

DELEUZE, G.; GUATTARI, F. Introdução Rizoma. In: Mil platôs: capitalismo e esquizofrenia. 2. ed. São Paulo: Ed. 34, 2011, v. 1, p. 17-50.

DELEUZE, G. Espinosa, filosofia prática. São Paulo: Escuta, 2002.

DELEUZE, G.; PARNET, C. Diálogos. São Paulo: Escuta, 1998.

FRANCO, T. et al. A produção subjetiva da Estratégia Saúde da Família. In: FRANCO, T. B.; ANDRADE, C. S.; FERREIRA, V. S. C. (Org.). A produçâo subjetiva do cuidado: cartografias da estratégia saúde da família. São Paulo: Hucitec, 2009, p. 19-44.

HORTA, N. C.; SENA, R. R. Abordagem ao adolescente e ao jovem nas políticas públicas de saúde no Brasil: um estudo de revisão. Physis, Revista de Saúde Coletiva. Rio de Janeiro, v. 20, n. 2, p. 475-495, 2010.

KVALE, S.; BRINKMANN, S. Interviews: Learning the craft of qualitative research interviewing. 2. ed. London: Sage, 2009.

LAGE, Â. M. D.; MOURA, L. R.; HORTA, N. C. Abordagem ao Adolescente e ao Jovem na Atenção Primária. In: SOUZA, M. C. M. R.; HORTA, N. C. Enfermagem em saúde coletiva: teoria e prática. Rio de Janeiro: Guanabara Koogan, 2012.

LISBOA, C. S. M.; WENDT G. W.; PUREZA, J. R. Mitos e fatos sobre o bullying: Orientações para pais e profissionais. Novo Hamburgo: Sinopsys Editora, 2014.

LISBOA, C.; EBERT, G. Violência na escolar: reflexão sobre as causas e propostas de açóes preventivas e focais. In: HABIGZANG, L. F.; KOLLER. S. H. Violência contra crianças e adolescentes: Teoria, pesquisa e prática. Porto Alegre: Artmed, 2012, p. 190-202.

LOPES NETO, A. A. Bullying: saber identificar e como prevenir. São Paulo: Brasiliense; 2011, p. 43-6.

MACHADO, A. L.; COLVERO, L. Histórias do grupo de pesquisa da subjetividade em saúde. In: MACHADO, A. L.; COLVERO, L.; RODOLPHO, J. R. C. (Orgs.). Saúde Mental: cuidado e subjetividade. São Caetano do Sul, SP: Difusão Editora; Rio de Janeiro: Editora Senac Rio de Janeiro, 2013.

MACHADO, A. L. et al. Subjetividade e pós-modernidade na enfermagem. Revista Eletrônica de Enfermagem. Goiania, v. 11, n. 4, p. 1031-6, 2009.

MACHADO, A. L.; COLVERO, L. A. O cuidado de enfermagem: olhando através da subjetividade. Acta Paulista de Enfermagem. São Paulo, v. 2, n. 12, p. 66-72, 1999.

MAFFESOLI, M. O ritmo da vida: variaçóes sobre o imaginário pós-moderno. Trad. de Clóvis Marques. Rio de Janeiro: Record, 2007. 
MARTINES, W. R. V.; MACHADO, A. L. Produção de cuidado e subjetividade. Rev Bras Enferm. Brasília, v. 63, n. 2, p. 328-33, 2010.

NASCIMENTO, A. M. T.; MENEZES, J. A. Intimidações na adolescência: expressóes da violência entre pares na cultura escolar. Psicologia \& Sociedade. Belo Horizonte, v. 25, n. 1, p. 142-151, 2013.

OLIVEIRA, T. R. M.; PARAÍSO, M. A. Mapas, dança, desenhos: a cartografia como método de pesquisa em educação. Pro-Posições. Campinas, v. 23, n. 3, p. 159-178, 2012.

OLWEUS, D. Sweden. In: SMITH, P. K. et al. (Eds.). The nature of school bullying: A crossnational perspective. New York: Routledge, 1999, p. 7-27.

PAULON, S. M. A análise de implicação como ferramenta na pesquisa-intervenção. Psicologia \& Sociedade. Belo Horizonte, v. 17, n. 3, p. 16-23, 2005.

PASSOS, E.; KASTRUP, V.; TEDESCO, S. Pistas do método cartográfico: a experiência da pesquisa e o plano comum. Porto Alegre: Sulina, 2014.

PELBART, P. P. A vertigem por um fio: políticas da subjetividade contemporânea. São Paulo: Iluminuras, 2000.

PERES, V. L. A.; MARTINS, L. R. R. A Produção subjetiva da violência nas escolas: indicador de sentido para avaliaçáo e desenvolvimento de política educacional. Revista Psicopedagogia. São Paulo, v. 29, n. 90, p. 320-9, 2012.

PIGOZI, P. L.; JONES BARTOLI, A. The school nurses' experiences in dealing with bullying situations. The Journal of School Nursing. Chicago USA v. 32, n. 3, p. 177-85, 2016.

ROLNIK, S. Subjetividade antropofágica. In: MACHADO, L. D.; LAVRADOR, M. C. C.; BARROS, M. E. B. (Orgs.). Texturas de psicologia: subjetividade política no contemporâneo. Sáo Paulo: Casa do Psicólogo, 2002, p. 11-28.

SAINIO, M. et al. Victims and their defenders: A dyadic approach. International Journal of Behavioral Development. Florida USA, v. 35, p. 144-151, 2011.

SALMIVALLI, C.; VOETEN, M.; POSKIPARTA, E. Bystanders Matter: Associations Between Reinforcing, Defending, and the Frequency of Bullying Behavior in Classrooms. Journal of Clinical Child \& Adolescent Psychology. USA, v. 40, n. 5, p. 668-67, 2011.

SMITH, P. K. Understanding school bullying: Its nature and prevention strategies. London: Sage, 2014.

SMITH, P. K.; DEL BARRIO, C.; TOKUNAGA, R. Definitions of bullying and cyberbullying: How useful are the terms? In: BAUMAN, S.; WALKER, J.; CROSS, D. (Eds.). Principles of cyberbullying research: Definition, methods, and measures. New York: Routledge, 2013. p. 64-86. 
SMITH, P. K.; MORITA, Y. Introduction. In: SMITH, Peter K. et al. (Eds.). The nature of school bullying: A cross-national perspective. New York: Routledge, 1999, p. 1.

SMITH, P. K.; SHARP, S. (Eds.). School bullying: Insights and perspectives. London: Routledge, 1994.

TEDESCO, S.; SADE, C.; CALIMAN, L. V. A entrevista em pesquisa cartográfica: a experiência do dizer. In: PASSOS, E.; KASTRUP, V.; TEDESCO, S. Pistas do método cartográfico: a experiência da pesquisa e o plano comum. Porto Alegre: Sulina, 2014 v. 2, p. 92-127.

YEN, C. et al. Association between school bullying levels/types and mental health problems among Taiwanese adolescents. Comprehensive Psychiatry. New York USA, v. 55, p. 405-13, 2014.

\section{Agradecimentos}

Agradeço à CAPES (Coordenação de Aperfeiçoamento de Pessoal de Nível Superior) pela concessão da bolsa durante o desenvolvimento deste estudo. 


\section{Abstract}

\section{The subjective production of care: a cartography of school bullying}

This article intends to understand how the subjective production of care to a teenager victim of bullying occurs in his community. The production of subjectivities is linked to the daily life of the adolescent, the relationships he builds and the support generated by the community in which he is inserted. The cartographic research sought to access, through semistructured interviews, the experiences, background and the path woven by him in search of protection. It discusses the violence suffered, his routes, self-care and support networks. The care produced proved to be oscillating throughout the territory. The school used specific strategies in relation to bullying and the health sector seems not to have reached the psychic dimension of suffering. However, in the nucleus of the family and of friends it was possible to inaugurate other forms of affection and attention to the mental health of the adolescent. The cartographic interview allowed to outline, from the perspective of the adolescent, the fragile care offered by his community in relation to bullying. It is pointed out that health actions, in order to be effective, must also consider the subjectivities and singularities of adolescents, that is, to ensure care with respect to differences and to stimulate the protagonism of young people in their territory of passage.

> Keywords: bullying; adolescent; cartography; subjectivity; Primary Health Care. 